\title{
CPTAC Follow-Up Form Terminology
}

National Cancer Institute

\section{Source}

National Cancer Institute. CPTAC Follow-Up Form Terminology. NCI Thesaurus. Code C156955.

Terminology used in support of the data collection efforts of the Clinical Proteomic

Tumor Analysis Consortium (CPTAC) with the focus on Follow-Up Form data. 